\title{
Interactive Mobile Applications to Support the Teaching of Reading and Writing of Spanish for Children in Primary Education
}

\author{
https://doi.org/10.3991/ijim.v14i14.14925 \\ Eduardo Hernández-Campos, Carlos R. Jaimez-González ( $\left.{ }^{\bowtie}\right)$, \\ Betzabet García-Mendoza \\ Universidad Autónoma Metropolitana, Ciudad de México, México \\ cjaimez@correo.cua.uam.mx
}

\begin{abstract}
In the educational process, literacy is considered as a fundamental part, which focuses on the ability to read and write. Reading and writing are processes that, although they have features in common, they may not be developed in parallel, but both are encompassed in teaching methods that aim to develop these two skills at the same time. Interactive mobile applications can be part of a strategy to support the teaching of reading and writing skills. This paper presents a review of five interactive mobile applications to support the teaching of Spanish reading and writing skills. Mobile applications were analyzed based on their general features and the activities they have. The following general features were taken into consideration: the existence of voice assistants, supporting characters, language selection, progression of activities, creation of avatars, variable difficulty, progress panel, images, among others. The activities considered for the revision were those that allow completing syllables, completing words from letters, completing words from syllables, completing sentences, relating images to words, among others.
\end{abstract}

Keywords-Interactive mobile application, educational technology, literacy, primary education, reading and writing skills.

\section{Introduction}

Education is one of the main pillars for the advancement and progress of human beings and of society in general. In addition to providing academic knowledge, education enriches individuals by giving them tools to contribute to society [1].

In the educational process, literacy is established as a fundamental part, which focuses on the ability to know how to read and write; however, this concept goes beyond this definition. UNESCO defines literacy as "the ability to identify, interpret, create, communicate and calculate, using printed and written material in different contexts. Literacy is a learning process that enables people to achieve personal goals, develop their knowledge and potential and fully participate in the life of the community and society as a whole" [2]. 
Literacy enables the development and participation of individuals in society, it is a force for sustainable development, as it gives individuals with analytical, critical, communicative, interpretative and creative capacities. In contrast, the lack of these skills or abilities is known as illiteracy.

In the "Action Plan to eradicate illiteracy before the year 2000" published by UNESCO [3], policies and actions were established that should be carried out by UNESCO member countries to achieve the progressive elimination of illiteracy in the world. By the year 2000, illiteracy rates in Latin America had decreased, for example, Mexico, which in 1990 had an estimate of $12.4 \%$, had $9.5 \%$ in 2000 [4]. In the following years, Mexico managed to further decrease these figures, reaching $5.5 \%$ of illiterate Mexicans by 2015.

Education processes can benefit from the new technologies which, according to UNESCO, "can facilitate universal access to education, reduce learning differences, support teacher development, improve quality and relevance of learning, reinforce integration and improve the management and administration of education" [5].

Mexico as a member country of the Organization for Economic Co-operation and Development (OECD) participates in the Program for the International Evaluation of Students (PISA), which is a test that aims to evaluate young people who have completed their basic education (primary and secondary). The test is carried out every three years, covers the three basic knowledge areas (Mathematics, Scientific Competences and Reading Areas) and is carried out on 15-year-olds, regardless of their academic level. Its objective is to provide data and statistics that allow member countries to take political and social measures to improve educational quality [6].

According to the results of the 2015 tests of the 72 participating countries, Mexico obtained the 57th place in the Science area, the 55th place in the Reading area and the 56th place in the Mathematics area. This is worrying and considering that the results of the 2018 test have not yet been formally published to date, a serious educational problem can be seen in the country [7].

Having a score of 423 in the reading area on the PISA test results, it can be seen that one of the main problems is the fact that young people do not understand or create a critical idea of what they read. The solution to this problem is complex, since it depends on an effort by society to improve the quality of reading skills, as well as by the government to establish better policies regarding education.

Clearly, reading problems have multiple facets, but the starting point is when a child begins to acquire those reading skills. Authors such as Emilia Ferreiro establishes that the literacy teaching process takes place in the initial stages of children's education and that correct teaching is essential for adult life [8]. It is in this initial literacy process, in which through games and activities children learn to formulate words and understand their meaning. In order to support this process, didactic games based on drawings and words to be completed are used, it is in this place where the use of digital tools could help and facilitate the teaching processes of reading and writing.

Information and Communication Technologies (ICT) are important resources, since they allow access to various forms of education, which are attractive and allow learning in a playful way. Furthermore, ICT allows learning to be organic, since children will learn at their own rhythm, but being monitored by teachers all the time [9]. 


\section{Theoretical Framework}

In order to start, the meaning of the concept literacy should be known, which can be defined as the set of processes that allow individuals to develop the skills necessary to translate knowledge into texts and to extract information from them.

The author Ferreiro [10] establishes that reading and writing is a single process that contains the necessary skills to be able to read and write, she establishes that these are not processes that are separate, since both depend on a subject and an object of knowledge, which means that one activity cannot be carried out without the other.

On the other hand, there are authors who make a distinction between the process of reading and writing; for example, Estalayo and Vega [11] establish that the term literacy is wrong, since the processes of reading and writing are different capacities, but they accept that the process of writing is only possible if reading has already been achieved.

In order to better identify the meaning of reading and writing, the paper "Challenges of early literacy" by Motta, Cagnolo and Martiarena, can be taken into consideration, since it establishes that: "the term is linked to the ability to read and write; ... we will take the following definitions: reading is to understand, and writing is to produce meaning" [12].

Therefore, reading and writing are processes that, although they have features in common, they may not be developed in parallel, but both are encompassed in teaching methods that aim to develop these two skills at the same time; these methods allow the skills to be developed. Because of this, some methods used in the literacy process are briefly reviewed.

In the research work "Initial literacy from the psychogenetic approach" by Álvarez and Hasbun [13], the following teaching methods are mentioned.

In order to start, the meaning of the concept literacy should be known, which can be defined as the set of processes that allow individuals to develop the skills necessary to translate knowledge into texts and to extract information from them.

The author Ferreiro [10] establishes that reading and writing is a single process that contains the necessary skills to be able to read and write, she establishes that these are not processes that are separate, since both depend on a subject and an object of knowledge, which means that one activity cannot be carried out without the other.

On the other hand, there are authors who make a distinction between the process of reading and writing; for example, Estalayo and Vega [11] establish that the term literacy is wrong, since the processes of reading and writing are different capacities, but they accept that the process of writing is only possible if reading has already been achieved.

In order to better identify the meaning of reading and writing, the paper "Challenges of early literacy" by Motta, Cagnolo and Martiarena, can be taken into consideration, since it establishes that: “... the term is linked to the ability to read and write; ... we will take the following definitions: reading is to understand, and writing is to produce meaning" [12].

Therefore, reading and writing are processes that, although they have features in common, they may not be developed in parallel, but both are encompassed in teaching 
methods that aim to develop these two skills at the same time; these methods allow the skills to be developed. Because of this, some methods used in the literacy process are briefly reviewed.

In the research work "Initial literacy from the psychogenetic approach" by Álvarez and Hasbun [13], the following teaching methods are mentioned:

Alphabetical method: at the beginning the letters are taught in alphabetical order, later it is taught how to spell words, then it is continued with formations and combinations of syllables, and finally it ends with simple words and sentences.

Onomatopoeic method: It is intended to teach through associations between phonemes and familiar sounds. For example, the syllable "Mu" in Spanish is related to the sound coming from cows.

Phonetic method: It is taught from the phoneme of each letter, which is related to the graphic representation of that letter, then words are formed by means of the sounds corresponding to each letter.

Syllabic method: It begins by teaching the vowels with their corresponding sounds through images or words, and then it introduces syllables, then combinations of syllables are taught in order to complete words.

Generated word method: Children are taught complete words, which must be associated with images and then decompose into their elements, moving from words to syllables and from syllables to letters.

It is observed that some of these methods share features such as the progression of particular to specific elements, relationship between elements with sounds, relationship between words and letters with images and combination of elements. These features are very useful, since they allow the activities of each method to be translated to digital systems in a simple way.

There are different systems within the educational environment that serve as support for both students and teachers. Kulik [14] establishes five different activities that systems perform within the educational environment:

Tools to carry out various activities: They consist of support systems that are used during educational activities, libraries, programming languages, integrated development environments, email, etc.

Integrated learning systems: They comprise a set of recreational activities that the individual performs, additionally they contain progress records that the teacher evaluates, for example, the systems used in the self-access laboratories of Spanish lessons.

Communication networks: Systems focused on the interaction of students and teachers through groups or forums that can be used outside the classroom.

Interactive learning environments: Systems focused on providing information to students while proposing activities in which the student is the key piece.

In the research work "Digital interactive activities as support tools in the literacy process in children with moderate intellectual disabilities" by Morales, Gómez, Katt and Fonseca [15], the Assessment of Support Areas (EVAA) system is presented, which main objective is to serve as a support tool in the literacy process; based on phonetic and onomatopoeic methods, it aims to further expand the scope of the systems. The results of this research showed that digital systems allow teachers new and 
innovative ways of teaching, since they are more attractive to children and allow them to develop new skills.

These systems are intended to serve educational purposes and can be classified into different categories, which were presented by Montoya [16].

Closed: They transfer knowledge from the repetition of activities, their content is fixed, and when they are completed they are not to useful anymore for the individual.

Semi-open: Similar to closed, but these allow modifying some features, such as difficulty, number of attempts, time limit, etc.

Open: They allow the teacher to create exercises or activities, which provide greater flexibility.

Tutorials: The system serves as a specific support adapted to teaching a task, without concrete interaction.

Simulations and pedagogical games: They aim to teach through games, which at first glance do not seem to be educational.

Considering the categories established by Montoya and the methods of teaching reading and writing skills, we can establish some general features for a system that intends to serve as a support tool in the literacy process.

In the words of Montoya, on the capacity of the systems with an open approach, he mentions that these "tend to be very successful among beginners as they are easy to use and we would venture to say that they are even more used in schools than other programs" [16]. Taking this idea into account, a system that intends to serve as a support tool must have an open approach, since it presents a greater interaction between the teacher and the student; therefore, the system will not replace the teacher. The system, having an open approach, will have greater flexibility, which will allow for greater adaptation to the various teaching methods. The system will not only be focused on a single method, but will be able to adapt to create new content.

\section{Review of Mobile Applications}

This section presents a review of five interactive mobile applications, which focus on the process of teaching reading and writing skills through games, based on the methods mentioned in the previous section.

\subsection{First words grin and uipi learn to read}

It is a mobile application developed by Educaplanet S. L. [17], it is aimed at children from three to seven years old; its main purpose is to improve children's reading skills. To achieve this, the application has a collection of 200 words with which children carry out various activities. The game interface is colorful, it uses supporting characters and can create an avatar to attract children's attention. There is the possibility of progress in the game by collecting fruits that are obtained when the system activities are carried out correctly.

The application contains five different activities, which consist of simple writing and relationship tasks, these activities are: dragging images to a particular position, 
matching an image with its corresponding word, writing the name of an image, matching a word with its corresponding image and a memory game.

The system provides users with five activities, but it is limited to ten animal-related words for those who want to use the free version of the game, this would be $5 \%$ of the words available in the system. According to the developer's official web site, it is possible to obtain discounts for classrooms, depending on the number of licenses required to use the system.

The 200 words available in the system are in Spanish so that they can be heard by children and thus achieve a more interactive application. On the other hand, the system has audio instructions; additionally, the system has the possibility of recording the children's voices to achieve even more interactivity and to make it easier to relate the words. The following paragraphs describe the activities.

Write words: The purpose of the game is to drag the letters to the corresponding boxes, in order to complete the name of the animal at the top, as shown in Figure 1. The game has two difficulties: the first one shows the word in transparent letters and the second does not show this help, so the child should pay attention to the representative image and the instructions given by the characters.

Image-word relationship: This activity focuses on relating the image presented at the top with the corresponding word. In order to complete this activity, the child must be able to read the three words and choose the correct one. Like the previous activity, it has two difficulties: the first has hearing aid and the second does not, so the user must pay attention to the written words.

Word-image relationship: It is similar to the previous one, but now a word is presented in the central part and three images. The user must select the correct image; the hearing aid will be present depending on the difficulty.

Additionally, the game allows the user to change the font by choosing between three variants: uppercase, lowercase and italic. On the other hand, the system contains a progress section, which shows the percentage of activities carried out with the number of errors and correct answers.

The system contains a section with a log in which you can see in detail the time when the various activities were carried out and the number of errors and correct answers. These sections can be sent by email to have more control of the children's progress. 


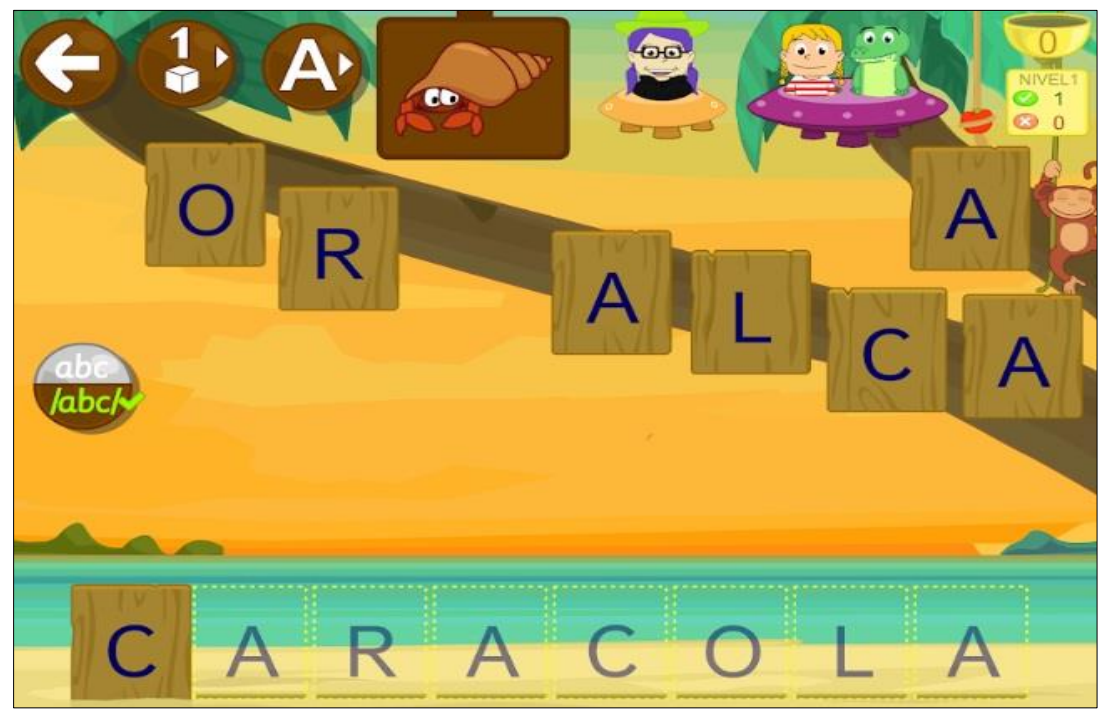

Fig. 1. Activity to drag letters to the corresponding boxes

\subsection{Learn to read 2 with grin and upi}

This mobile application was also developed by Educaplanet S. L. [18]. Its purpose is to teach reading and writing with exercises that focus on teaching syllables; it aims to reinforce skills of visual and audio memorization, association, discrimination, literacy and comprehension. Due to the complexity of some exercises, this mobile application is intended for children from five to eight years old.

The system features 25 lessons divided into five levels to view syllables, locked and inverse syllables. The free version of the game allows access to a lesson with $1.25 \%$ of available content.

It shares many features of the game "First words Grin and Uipi Learn to read", such as the characters, the possibility of creating an avatar and the possibility of changing the font. Unlike the aforementioned system, it has 12 activities: listening to the syllables of a word, dragging syllables, forming syllables, selecting the syllable, forming words by means of syllables, forming words, searching for the word, writing words, listening to sentences, make sentences using words, write a sentence, and read and answer a question. The system focuses on teaching syllables first, then words, and finally sentences. This represents an interesting complexity curve, since it goes from the basics to the comprehension of simple texts. The system can be divided into five types of activities.

Listening: These activities depend entirely on listening and there is little interaction with the user, since the user only has to press the words in order for them to be mentioned. 
Searching for items: These activities focus on searching for a word or syllable and dragging or selecting it. The simplest activity focuses on dragging syllables to the corresponding box.

Forming elements by dragging: These activities have the main feature of forming syllables, words and sentences, through their elements. The first of them focuses on forming syllables through their letters, for this the user must drag a letter from a drawer and place it in the box.

The last activity in this group is to drag the words into the corresponding boxes to form a sentence. The difficulty of these four activities depends on showing transparent letters, so the child must pay attention to the instructions given.

Form elements by typing: The following activities consist of forming elements by typing the corresponding letters. The first one, shown in Figure 2, consists of typing a word, the next activity will ask you to type a sentence; for these two activities, the difficulty depends on whether or not the letters that are not part of the sentence or word are available on the keyboard.

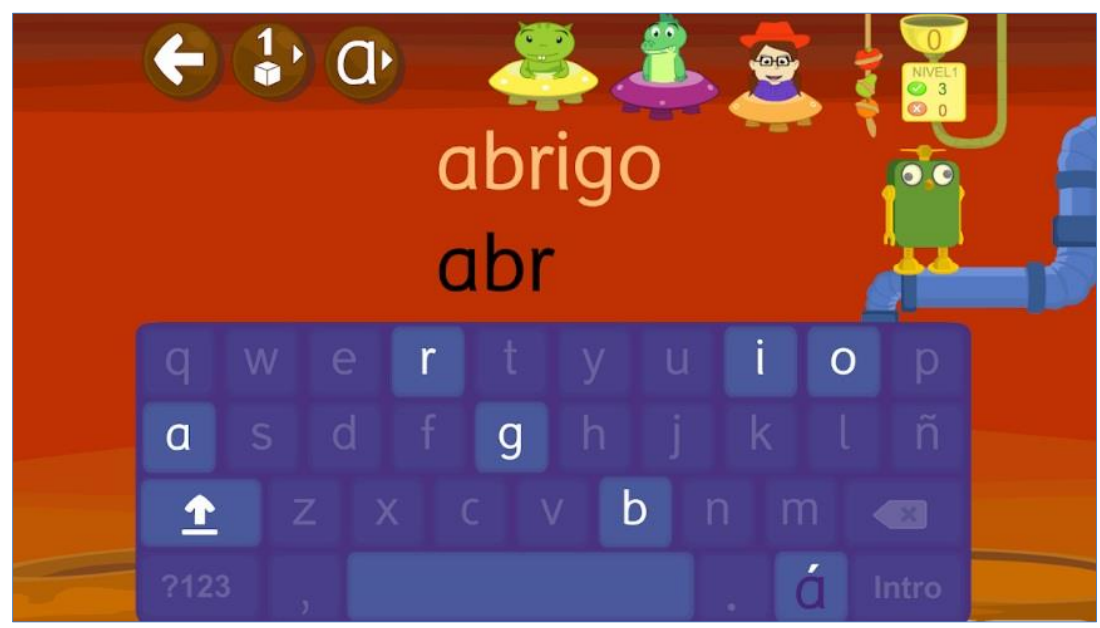

Fig. 2. Activity to type a word from a keyboard

Reading comprehension: This last activity seems to be the most complex of all, since it asks the child to read a short sentence and answer a question. The comprehension exercise can be very difficult for children who are just beginning to read. In this activity the sentence is read by the characters of the system, but these can be deactivated according to the difficulty, which adds more complexity to the child.

\subsection{Learn to read syllabary}

It is a mobile application developed by EduApps [19], which was thought for children of four years old and older. It presents a simple game that aims to educate children through phonetics, syllables and word formation. The configuration of the game 
allows to change the font; it also contains a voice that presents the words in the mobile application, but it is computer generated.

The application presents 97 levels for free that contain between five and ten activities each; this means that there are around 1000 different exercises; every eight to ten levels a test is presented. Unlike the normal levels, the test contains about 12 exercises, which are of three types with similar features.

The first exercise consists of selecting the first letter of a word, which is related to an image. The second exercise consists of selecting the first syllable of a word, which is related to an image again. The last activity is to select all the syllables of a word. Figure 3 shows the arrangement of the elements of this activity; in this case, the child must select three syllables, from the set of syllables below the image.

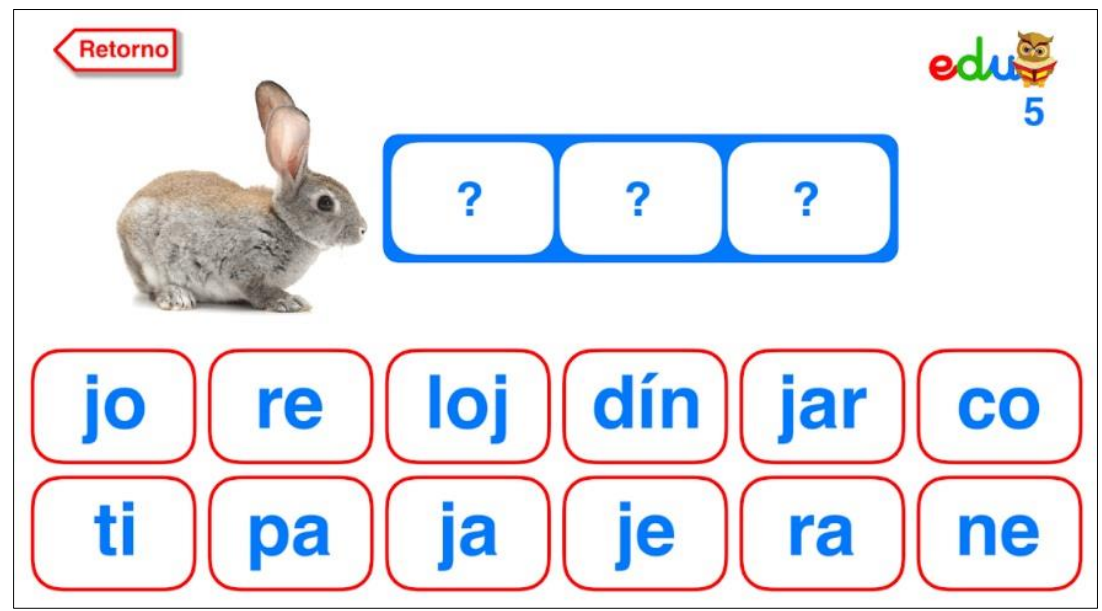

Fig. 3. Activity to drag all the syllables that compose a word

Because the images shown in the mobile application can have multiple names and could be confusing for the children, the system instructs them with a voice, which reads the words and syllables as well.

\subsection{Learn to spell and write}

It is a system developed by Orange Studios Games [20], which was thought for children of all ages; it is an educational game that aims to teach reading and writing and also to recognize words in English and Spanish.

The game interface is colorful; it uses illustrations and buttons that make the application very striking. The application is accompanied at all times by melodies that can be disabled from the options menu, it also allows the user to change the language choosing between Spanish and English.

The system presents a total of ten levels, of which seven are available from the beginning and the last three must be unlocked with coins earned by completing the activities. The levels are defined by the following categories: Animals, Food, Clothing, 
Christmas, Home, Tools, Vehicles, Holidays and Instruments. The game shown in Figure 4 consists of completing words by dragging the letters that compose them. Depending on the level of difficulty, the word to be completed will be shown; it will be displayed in the boxes with transparent letters. The system contains a voice assistant that reads the selected words and letters, in this case the assistant does not give instructions to the user.

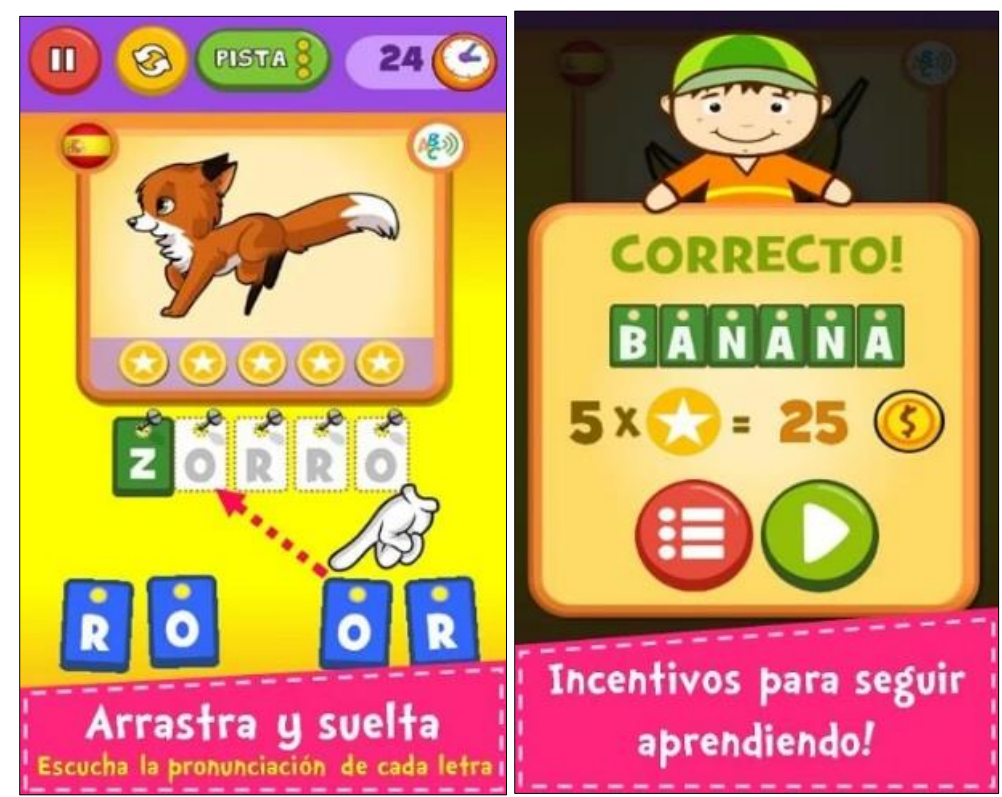

Fig. 4. Activity to complete words by dragging letters

A novelty that the game contains is a hint button and a limited number of attempts that translate into coins; depending on the number of letters in the word it will be the number of attempts allowed; for each error the coins will be lost until they run out of attempts. Once the word is completed, the number of coins is received depending on the number of errors. On the other hand, the game has a clock in the upper right corner that counts down, once the time is finished one coin will be lost.

The system is free, but it has the drawback of showing advertisements during the execution of the game, which can be problematic since it is an application designed for children; ads can be removed, but the ad-free version must be purchased.

\subsection{The hangman}

It is a mobile application developed by Quarzo Apps [21], its main purpose is to entertain and at the same time to teach new words in English and Spanish. The system presents a simple interface that shows the multiple options it contains, such as deactivating or activating background music, changing languages, displaying notifications 
and the type of orientation of the device (horizontal or vertical). The system also implements a considerable number of avatars, which can be unlocked using coins earned by completing the activities.

It only has one game mode, but it contains around 30 different categories, which contain approximately ten words each, which translates into approximately 300 words available to play. Figure 5 shows the game, displaying the category to which the word belongs, the number of spaces that correspond to the number of letters and a space where the hangman will be appearing; each word has eight attempts.

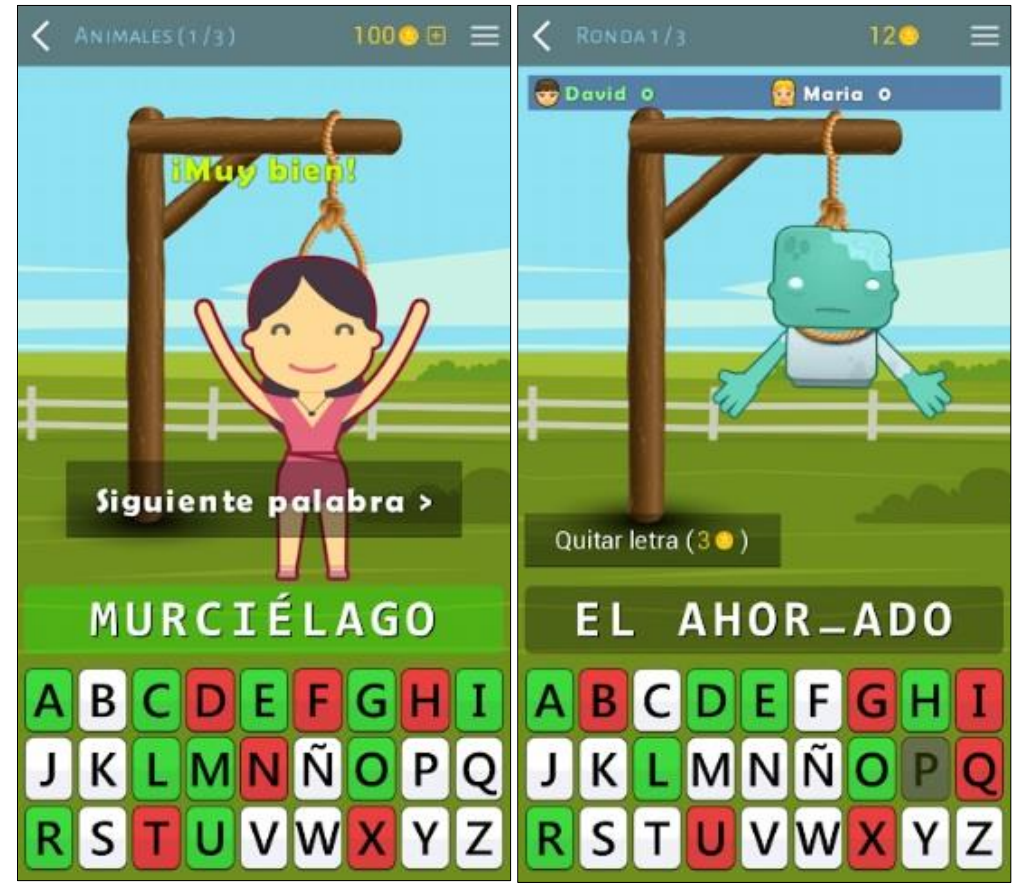

Fig. 5. Hangman game with two different words

The importance of evaluating a game with these features lies in the mechanics of the game, which is similar to those of previous mobile applications reviewed and allows viewing these activities from another perspective, which aims to entertain the user while teaching new words.

\section{Comparative Analysis}

In this section a comparison of the evaluated mobile applications is provided, from their general features to the mechanisms used in their activities. The first elements to take into account are the general features of the mobile applications.

Table 1 shows a comparison of the general features of the interactive mobile applications described above, which appear in the columns as follows: M1) First words 
Grin and Uipi Learn to read; M2) Learn to read 2 with Grin and Upi; M3) Learn to read Syllabary; M4) Learn to Spell and Write; M5) The Hangman.

The tick indicates that the mobile application has the feature, while the cross indicates that the mobile application does not have it. A description of the general features is presented below the table.

Table 1. General features of the analyzed mobile applications

\begin{tabular}{|l|c|c|c|c|c|}
\hline \multicolumn{1}{|c|}{ Features } & M1 & M2 & M3 & M4 & M5 \\
\hline 1) Supporting characters & $\checkmark$ & $\checkmark$ & $\mathbf{x}$ & $\checkmark$ & $\mathbf{x}$ \\
\hline 2) Voice assistant & $\checkmark$ & $\checkmark$ & $\checkmark$ & $\checkmark$ & $\mathbf{x}$ \\
\hline 3) Language & $\mathbf{x}$ & $\mathbf{x}$ & $\mathbf{x}$ & $\checkmark$ & $\checkmark$ \\
\hline 4) Progression & $\checkmark$ & $\checkmark$ & $\mathbf{x}$ & $\checkmark$ & $\checkmark$ \\
\hline 5) Avatar & $\checkmark$ & $\checkmark$ & $\mathbf{x}$ & $\mathbf{x}$ & $\checkmark$ \\
\hline 6) Variable difficulty & $\checkmark$ & $\checkmark$ & $\checkmark$ & $\mathbf{x}$ & $\checkmark$ \\
\hline 7) Progress panel & $\checkmark$ & $\checkmark$ & $\mathbf{x}$ & $\mathbf{x}$ & $\mathbf{x}$ \\
\hline 8) Different fonts & $\checkmark$ & $\checkmark$ & $\checkmark$ & $\mathbf{x}$ & $\mathbf{x}$ \\
\hline 9) Images & $\checkmark$ & $\checkmark$ & $\checkmark$ & $\mathbf{x}$ & $\checkmark$ \\
\hline
\end{tabular}

Supporting characters: the mobile application is accompanied by one or more supporting characters.

Voice assistant: The mobile application provides help through a voice assistant, it also reads letters, words and gives instructions.

Language: The mobile application has the option to change the language of the words or change the language of the mobile application interface.

Progression: The mobile application has some kind of progression or reward.

Avatar: The mobile application allows the user to select an avatar and customize it.

Variable difficulty: The mobile application allows the user to choose between two or more levels of difficulty.

Progress panel: The mobile application allows verifying the number of activities carried out and displays them in a panel with errors and correct answers or scores.

Different fonts: The mobile application allows the user to switch between various types of letters for the activities presented.

Images: The mobile application uses images that represent the words within the activities displayed.

Table 2 shows a comparison of the types of mechanisms for the activities that are carried out in the mobile applications described above, which appear again in the columns in the same order in which they were presented in Table 1. The tick indicates that the mobile application has the mechanism, while the cross indicates that the mobile application does not have it. A description of the types of mechanisms for the activities is presented below the table. 
Table 2. Mechanisms for the activities presented in the analyzed mobile applications

\begin{tabular}{|l|c|c|c|c|c|}
\hline \multicolumn{1}{|c|}{ Mechanisms } & M1 & M2 & M3 & M4 & M5 \\
\hline 1) Boxes & $\checkmark$ & $\checkmark$ & $\checkmark$ & $\checkmark$ & $\mathbf{x}$ \\
\hline 2) Keyboard & $\mathbf{x}$ & $\checkmark$ & $\mathbf{x}$ & $\mathbf{x}$ & $\checkmark$ \\
\hline 3) Complete syllables & $\mathbf{x}$ & $\checkmark$ & $\mathbf{x}$ & $\mathbf{x}$ & $\mathbf{x}$ \\
\hline 4) Complete words (letters) & $\checkmark$ & $\checkmark$ & $\checkmark$ & $\checkmark$ & $\checkmark$ \\
\hline 5) Complete words (syllables) & $\mathbf{x}$ & $\checkmark$ & $\checkmark$ & $\mathbf{x}$ & $\mathbf{x}$ \\
\hline 6) Complete sentences & $\mathbf{x}$ & $\checkmark$ & $\mathbf{x}$ & $\mathbf{x}$ & $\mathbf{x}$ \\
\hline 7) Image-word relationship & $\checkmark$ & $\mathbf{x}$ & $\mathbf{x}$ & $\mathbf{x}$ & $\mathbf{x}$ \\
\hline 8) Word-image relationship & $\checkmark$ & $\mathbf{x}$ & $\mathbf{x}$ & $\mathbf{x}$ & $\mathbf{x}$ \\
\hline
\end{tabular}

Boxes: They focus on dragging items from a box to another corresponding box.

Keyboard: They focus on pressing buttons on a keyboard that may be virtual.

Complete syllables: Syllables must be formed by means of their elements.

Complete words (letters): They focus on completing words using the letters that compose them.

Completing words (syllables): They focus on completing words using the syllables that compose them.

Complete sentences: Sentences must be formed by means of syllables or words.

Image-word relationship: An image is displayed and the correct word must be selected from among several options.

Word-image relationship: A word is displayed and the correct image must be selected from among several options.

\section{Conclusion}

Reading and writing are two processes that allow individuals to develop the necessary skills to translate knowledge into texts and to extract information from them. Given the importance of these processes, this paper presented a comparative analysis of five interactive mobile applications to support the teaching of reading and writing of Spanish for children in primary education. The analysis was carried out in two ways: observing the general features of the mobile applications, and secondly, analyzing the mechanisms of the activities they provide.

Regarding the general features, it is observed that the mobile applications have supporting characters, voice assistants, different languages, activity progression, avatars, variable difficulty, progress panel, support images, among others. Regarding the types of mechanisms for preparing the activities, the following are mainly used: complete syllables, complete words from letters, complete words from syllables, complete sentences, relate an image to a word to be selected from several words, and relate a word to an image to be selected from several images.

It was observed that the mobile applications are not flexible and customizable enough. We plan the creation of a mobile application that serves as a tool in the process of reading and writing of Spanish for children in primary education, in which the teacher takes an active role establishing rules and various activities. The objective of the proposal will be to design and implement a customizable mobile application that 
allows generating didactic games to support the teaching process of reading and writing in children of primary schools.

Taking advantage of the customizable feature of the mobile application proposed, it is also planned to extend its functionality with multimedia materials for supporting Mexican indigenous languages, such as the materials used for the Zapoteca language, described in [22], which are oriented to students of primary school and aim to address some current necessities in indigenous education. Another functionality to be considered in the mobile application is the capability of evaluating the reading skills of the students through different types of tests as shown in [23], which eventually would enhance reading literacy of elementary students.

The mobile application proposed will be divided into two parts: the first part will be developed for tutors or teachers and will allow the creation of blocks or categories of words. In order to create these blocks, the user must select from the existing words in the system, or they may enter words with their corresponding image, which will be stored in a database; the second part of the system will allow the user to play and carry out the activities previously defined (complete syllables, complete words from letters, complete words from syllables, complete sentences, relate an image to a word to be selected from several words, etc.), but the selection of words for the activities will be carried out randomly.

\section{References}

[1] UNESCO (2014). UNESCO indicators of culture for development. Available: https://es. unesco.org/creativity/sites/creativity/files/iucd_manual_metodologico_1.pdf

[2] UNESCO (2007). Glossary. Monitoring report of EPT. Available: http://www.unesco.org/ new/fileadmin/MULTIMEDIA/HQ/ED/pdf/gmr2011-glossary-es.pdf

[3] UNESCO (1989). Action plan to eradicate illiteracy before the year 2000. Available: https ://unesdoc.unesco.org/ark:/48223/pf0000083908_spa

[4] INEGI (2015). Cuéntame Analfabetismo. México. Available: http://cuentame.inegi.org. $\underline{\mathrm{mx} / \text { poblacion/analfabeta.aspx } \text { ?tema }=\mathrm{P}}$

[5] UNESCO (2019). ICT in education. Available: https://es.unesco.org/themes/tic-educacion

[6] OCDE (2006). The OECD PISA program what it is and what it is for. Available: https:// www.oecd.org/pisa/39730818.pdf

[7] INEE, (2016). INEE presents the results of Mexico in PISA 2015. Available: https://www. inee.edu.mx/presenta-el-inee-los-resultados-de-mexico-en-pisa-2015/

[8] Ferreiro, E. (1997). Literacy Theory and Practice. México: Siglo veintiuno.

[9] Pérez, C. (2006). ICT as a resource in access to literacy. Available: http://servicios.edu carm.es/templates/portal/ficheros/websDinamicas/97/t06.pdf

[10] Ferreiro, E. (2006). The writing before the letter. CPU-e, Revista de Investigación Educativa. No. 3 (july-december), pp. 1-52. Available: https://www.redalyc.org /pdf/2831/283121724001.pdf

[11] Estalayo V., Vega R. (2003). Read well. The Doman method adapted to school. Madrid, España: Biblioteca Nueva. 
[12] Motta B., Cagnolo G., Martiarena A., (2011). Desafíos de la alfabetización temprana. Available: https://docplayer.es/18089233-Desafios-de-la-alfabetizacion-temprana.html

[13] Álvarez D., Hasbun V. (2014). Alfabetización inicial desde el enfoque psicogenético. Tesis de Licenciatura, Santiago, Chile. Available: http://bibliotecadigital.academia.cl/bitstream/ handle/123456789/2913/TPDIF\%2051.pdf

[14] Kulik, J. (2003). Effects of using instructional technology in elementary and secondary schools: What controlled evaluation studies say. Available: https://www.ic.unicamp.br/ wainer/cursos/2s2004/impactos2004/Kulik_ITinK-12_Main_Report.pdf

[15] Morales, E., Gómez, E., Katt, L., Fonseca J. (2013). Actividades interactivas digitales como herramientas de apoyo en el proceso de lectoescritura en niños con discapacidad intelectual moderada. Congreso Interdisciplinario de Cuerpos Académicos, pp. 11-20. Available: https://dialnet.unirioja.es/servlet/articulo?codigo=4783879

[16] Montoya R. (2002). Computer and Disability: A practical guide to support people with special educational needs. Madrid, España: CEPE.

[17] Educaplanet (2017). First words Grin and Uipi Learn to read. Available: https://www.edu caplanet.com/educaplanet/primeras-palabras-grin/

[18] Educaplanet (2018). Learn to Read 2 with Grin and Uipi. Available: https://www.edu caplanet.com/educaplanet/aprender-a-leer-2-grin-uipi/

[19] EduApps (2018). Learn to read - Syllabary. Available: https://play.google.com/ store/apps/details?id=com.eduapps.silabario\&hl=es_M

[20] Orange Studios Games (2019). Learn to spell and write. Available: https://play.google. com/store/apps/details?id=com.orange.kids.learn.spell.write.words\&hl=es_MX

[21] Quarzo Apps (2019). The hangman (in Spanish). Available: https://play.google.com/ store/apps/details?id=com.quarzo.hangmanwords\&hl=es

[22] Garcia, I., Pacheco, C., Ruiz, J. (2011). Introducing an Etnosemiotic Approach to Develop Multimedia Material for Supporting the Alphabetization Process for a Mexican Indigenous Language. International Journal of Emerging Technologies in Learning, 6(3), pp. 42-48. http://dx.doi.org/ijet.v6i3.1660

[23] Picher, P., Ebner, M. (2015). Development of an Information System to Enhance Students Reading Literacy. International Journal of Emerging Technologies in Learning, 10(3), pp. 15-21. http://dx.doi.org/10.3991/ijet.v10i3.4457

\section{$7 \quad$ Authors}

Eduardo Hernández-Campos is a student of the Information Technologies and Systems undergraduate program at the Universidad Autónoma Metropolitana Campus Cuajimalpa, in Mexico City. His research interests include technologies for supporting education and web application development.

Carlos R. Jaimez-González is an Associate Professor at the Information Technologies Department at the Universidad Autónoma Metropolitana Campus Cuajimalpa, in Mexico City. He received his PhD degree in Computer Science from the University of Essex, United Kingdom in 2011. His research interests include technologies for supporting education, interoperability in distributed systems, XML and related tech- 
nologies, and the development of web and e-commerce applications. He has a distinction as a national researcher from the Mexican Government.

Betzabet García-Mendoza is an Associate Professor at the Information Technologies Department at the Universidad Autónoma Metropolitana Campus Cuajimalpa, in Mexico City. She received her MSc degree in Design, Information and Communication from the Universidad Autónoma Metropolitana. Her research interests include technologies for supporting education and web application development.

Article submitted 2020-04-16. Resubmitted 2020-05-23. Final acceptance 2020-05-23. Final version published as submitted by the authors. 